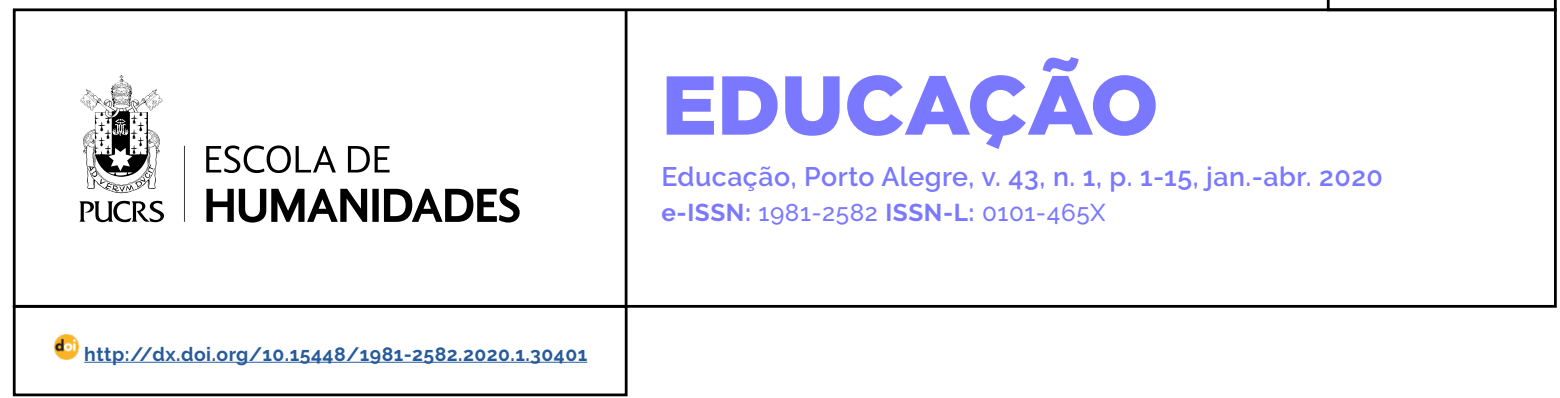

SEÇÃO:

\title{
Desafios da docência universitária: um olhar de professores formadores
}

\author{
Challenges of university teaching: a look of teacher trainers \\ Desafios de la docencia universitaria: una mirada de profesores formadores
}

\section{Thamiris Christine Mendes Berger ${ }^{1}$}

orcid.org/0000-0002-8614-2194

mendesthamirisc@hotmail.com

\section{Ana Lucia Pereira ${ }^{1}$ \\ orcid.org/0000-0003-0970-260X \\ ana.lucia.pereira.173@gmail.com}

\section{Cristina Costa}

orcid.org/0000-0002-2117-8479 cristina.costa@durham.ac.uk

Recebido em: 19 abr. 2018. Aprovado em: 30 out. 2019. Publicado em: 25 mai. 2020.
Resumo: A pesquisa tem como objetivo identificar os desafios da carreira docente universitária apontados por professores formadores. A abordagem é qualitativa e os dados foram coletados por meio de questionário com trinta e seis (36) professores que lecionam em cursos de licenciatura de uma universidade estadual do Paraná. Contou-se com a análise textual discursiva e os resultados apontam que os principais desafios enfrentados pelos formadores estão relacionados à preparação dos alunos para a graduação; condições profissionais e políticas públicas. A pesquisa também evidenciou que há muitas contradições no que tange ao papel que se almeja das instituições de ensino superior e o que realmente desempenham.

Palavras-chave: docência universitária, professor formador, carreira docente. universidade.

Abstract: The aim of the research is to identify the challenges of the university teaching career pointed out by teacher trainers. The approach is qualitative and the data was collected through the means of a questionnaire with thirty-six (36) teachers who teach in undergraduate courses at a state university in Paraná The discursive textual analysis was counted and the results show that the main challenges faced by the trainers are related to the students' preparation for graduation; professional conditions and public policies. The research also showed that there are many contradictions regarding the role of higher education institutions and what they really play.

Keywords: university teaching, teacher training, teaching career, university.

Resumen: La investigación tiene como objetivo identificar los desafíos de la carrera docente universitaria apuntados por profesores formadores. El enfoque es cualitativo y los datos fueron recolectados por medio de cuestionario con treinta y seis (36) profesores que enseñan en cursos de licenciatura de una universidad del estado de Paraná. Se contó con el análisis textual discursivo y los resultados apuntan que los principales desafíos enfrentados por los formadores están relacionados a la preparación de los alumnos para la graduación; condiciones profesionales y políticas públicas. La investigación también evidenció que hay muchas contradicciones en lo que se refiere al papel que se anhela para las instituciones de enseñanza superior y lo que realmente desempeñan.

Palabras clave: docencia universitária, profesor formador, carrera docente, universidad. 


\section{Introdução e aproximações teóricas}

Como denunciou Chaui (2001), a universidade no contexto atual desempenha o papel de adestramento de mão de obra dócil para o mercado de trabalho que é sempre incerto, produzindo, na maioria das vezes, sujeitos incompetentes nas áreas politica e social, além de fragmentar e limitar o conhecimento. Desse modo, a instituição universitária não é produtora de cultura como deveria ser, mas exerce a função de "dar a conhecer para que não se possa pensar" (2001, p. 62). Tal constatação sobre a função que de fato a instituição em questão exerce, revela exatamente o oposto dos ideais democráticos e contraria a perspectiva de universidade como instituição social criadora de cultura e produtora de conhecimento.

Para Severino (2002) há uma sensação generalizada de frustração no que se refere às promessas de desenvolvimento, progresso social e valorização da educação, demarcando assim uma crise profunda em todos os setores da vida humana na sociedade brasileira. Tal sensação acomete também às universidades que, como instituições educativas, sofrem processo de "corrosão interna" comprometendo a sua eficácia. Este panorama de crise afeta universidades públicas e particulares por meio do excessivo trabalho burocrático, da incapacidade de articulação de projetos de ações que vão além dos interesses imediatos e egocêntricos do mercado de trabalho, por exemplo, marcadas, ainda, pela ideologia da qualidade total neoliberal que permanece no imaginário nacional.

Consideramos que discutir os desafios que os professores universitários enfrentam no seu cotidiano profissional pode auxiliar nas discussões sobre a identidade e o processo de profissionalização docente. Sobre isso, Pimenta e Anastasiou (2014, p. 39) reforçam que: "o grau de qualificação é um fator-chave no fomento da qualidade em qualquer profissão, especialmente na educação, que experimenta constante mudança".

Segundo Pimenta e Anastasiou (2014, p. 103), o ensino na universidade tem como função:

a) pressupor dominio de um conjunto de conhecimentos, métodos e técnicas científicas que devem ser ensinados criticamente (...) condução a uma progressiva autonomia do aluno na busca de conhecimentos; o desenvolvimento de capacidade de reflexão; a habilidade de usar documentação; domínio científico e profissional do campo especifico;

b) considerar os processos de ensinar e aprender como atividade integrada à investigação:

c) propor substituição do ensino que se limita a transmissão de conteúdos teóricos por um ensino que constitua um processo de investigação do conhecimento;

d) integrar a atividade de investigação à atividade de ensinar do professor, o que requer trabalho em equipe;

e) buscar criar e recriar situações de aprendizagem;

f) valorizar a avaliação diagnóstica e compreensiva (...);

g) procurar conhecer o universo cognitivo e cultural dos alunos e, com base nisso, desenvolver processos de ensino e aprendizagem interativos e participativos.

Todas essas funções nos levam a refletir sobre quem são os professores que estão atuando nas universidades brasileiras e se eles têm formação adequada para dar conta de tais tarefas. A discussão sobre a formação e o papel do professor é polissêmica e acaba esbarrando em diferentes concepções e crenças que, muitas vezes, distorcem e se distanciam da verdadeira função do educador. Com isso, voltamo-nos para a problemática da identidade profissional docente e, também, nos faz refletir sobre as condições do exercicio da docência na contemporaneidade.

Pimenta e Anastasiou (2014), assim como Soares e Cunha (2010), explicitam a inexistência de uma formação especifica para a docência universitária e as suas implicações para o desenvolvimento profissional docente e a própria formação inicial de professores. Mas, afinal, quais são os conhecimentos, os saberes necessários para a formação do futuro professor para atuar em todas as modalidades de ensino? Como isso é trabalhado na sua formação e como se dá a 
formação do professor para exercer o magistério?

A pesquisa descrita no presente artigo aborda a docência no ensino superior e tem como objetivo principal identificar e analisar os desafios que os docentes formadores de uma universidade pública estadual enfrentam em seu cotidiano profissional.

\section{Universidade e docência universitária: tensões e intenções}

Existem diferentes visões sobre o papel da universidade no contexto atual, a compreendemos "como lócus em que ocorrem práticas institucionalizadas de produção de conhecimento" (Hey, 2008, p. 220) que, como campo acadêmico, incide em um dos principais agentes formadores de profissionais

Para Moraes (1998), existem três visões coexistentes acerca da universidade: a de prestação de serviços, de lugar de prática e ensino de pesquisa, ou seja, de produção de conhecimento e, ainda, como lugar privilegiado de preparação para o exercício profissional. De acordo com o mesmo autor, prevalecem quatro características especificas na universidade: 1) precisa permitir aos estudantes e professores acesso aos diferentes campos da cultura e da ciência; 2) nota-se o crescente peso e matricula na área das ciências exatas, biológicas e tecnológicas em detrimento das humanas e sociais; 3) crescente desenvolvimento de atividade de pós-graduação com a prática de pesquisa e ensino da mesma; e 4) a extensão de serviços à comunidade. Tais características nos remetem às discussões sobre o papel da universidade em suas três dimensões: o ensino, a pesquisa e a extensão, sem que haja exclusão de alguma delas.

Entendemos que a universidade possui como missão a integração ou indissociabilidade do ensino, da pesquisa e da extensão, não podendo admitir que a produção intelectual se dê de modo a separá-los, mas tendo como referência principal a pesquisa (Severino, 2002; Cunha, 2012; Pimenta \& Anastasiou, 2014). Segundo Severino (2002, p. 122), "aprende-se e ensina-se pesquisando", assim, o trabalho na universidade deve ampararse pela pesquisa, a qual assume o seu papel como eixo central, pois é por meio dela que se produz conhecimento, que, por sua vez, só é viabilizado através da extensão e do ensino.

Nessa mesma perspectiva, para Moraes (1998), universidade e professores que não pesquisam consequentemente não ensinam bem, deixando de exercer a sua finalidade de fato. Em contrapartida, Severino (2002) coloca que a tradição brasileira prioriza o ensino, concebido basicamente como transmissão de conhecimento, o que infelizmente é muito observado nas práticas pedagógicas docentes.

Cunha (2012) reitera as ideias dos pesquisadores anteriormente mencionados ao destacar que a tão discutida "indissociabilidade" entre ensino, pesquisa e extensão necessita ser mais valorizada e, principalmente, esclarecida, pois frequentemente o termo fica obscuro. A autora tanto questiona o real significado do termo tão disseminado atualmente quanto trata-se de abordar a função da universidade no contexto contemporâneo. Cunha (2012) conclui que existem múltiplas compreensões no que tange ao conceito e ao sentido de indissociabilidade e de seu constructo na expressão de qualidade da educação superior. Para a mesma estudiosa, essa constatação é um reforço para a ideia de que não há como estabelecer parâmetros únicos, universais e atemporais, de qualidade acadêmica.

Masetto (2003) enfatiza que algumas mudanças no século XX provocaram também transformações no ensino superior em alguns pontos: no processo de ensino, na pesquisa e seu incentivo, na parceria entre professor e alunos no processo de aprendizagem e, por fim, no próprio perfil docente.

A respeito do processo de ensino, Masetto (2003) coloca que nesse periodo se começou a pensar a aprendizagem discente de modo diferente, procurando aperfeiçoar a capacidade de pensar dos alunos para que fossem capazes de construir significados para o que estavam estudando, procurando construir o seu próprio conhecimento:

Superando a formação voltada apenas para o aspecto cognitivo, o que se busca é que o aluno em seus cursos superiores esteja desenvolvendo competências e habilidades que se esperam de um profissional capaz e de um cidadão responsável pelo desenvolvimento sua comunidade. (p. 20) 
No que se refere ao ponto de incentivo à pesquisa, Masetto (2003), assim como Cunha (2012), traça alguns acontecimentos que provocaram mudança na concepção de formação profissional meramente técnica. Após o periodo da ditadura militar em 1968 a criação de programas de pós-graduação e o surgimento de agências de financiamento e fomento, a pesquisa ganhou espaço na academia brasileira.

Pimenta e Anastasiou (2014) abordam a questão da valorização da pesquisa no processo de ensinar. Ser um reconhecido pesquisador não significa que terá excelência no desempenho pedagógico. Há que se compreender as diferenças entre o ensinar e o pesquisar e, ainda, se ensinar com pesquisa e ensinar a pesquisar. A pesquisa exige algumas variáveis: definição de sujeitos envolvidos, tempo, resultados, método. Já o ensinar também requer pensar nos elementos da pesquisa. Porém, as relações com as variáveis são outras.

Outro aspecto que foi se modificando foi a parceria entre o professor e o aluno no processo de aprendizagem. Há preocupações docentes com relação à participação e ao envolvimento dos alunos com o conteúdo que está sendo ensinado. Isso pois, compreende-se o aluno como sujeito do processo e não como mero coadjuvante: "A docência existe para que o aluno aprenda" (Masetto, 2003, p. 23).

Para que essa participação aconteça, envolve motivação e interesse dos alunos pelos conteúdos. Também é preciso dinamizar as relações entre discentes e docentes para facilitar a comunicação entre ambos a fim de que o alunado veja os professores como aliados na sua formação e não como obstáculo (Masetto, 2003).

Krasilchik (2009) ressalta a importância de conhecer os alunos com os quais trabalhamos para tratar adequadamente do que ocorre e deve ocorrer nas aulas. Nesse sentido, destacamos que o que orienta o trabalho docente são as posturas dos estudantes: "A análise da postura dos estudantes será orientadora para discussão do que se exige hoje de um professor universitário no exercicio da docência" (p. 149).

No que tange o perfil dos alunos que frequentam os cursos de graduação, é possivel dividi-los em superficiais e profundos, a partir do estudo de Marton e Saljo (1976 citado por Krasilchik, 2009). Para essa classificação, os pesquisadores investigaram como os alunos estudam e quais interesses visam atender.

O aluno superficial tem interesses externos "(...) quer receber boas notas, agradar professores, familiares e fazer bom papel no seu grupo" ( $p$. 153), as tarefas assumem imposições externas e o seu envolvimento pelo estudo é por obrigação. Já o aluno profundo tem outras motivações, ele quer compreender de fato e vai além do que é repassado na escola. Consulta bibliografias por conta, faz perguntas ao professor dentro e fora da aula, discute os temas com colegas, relaciona teoria com experiências cotidianas, foca o que é relevante, organiza o conhecimento em um todo coerente e busca conexões entre os temas e disciplinas: "Seu envolvimento com o estudo é prioritariamente o prazer de aprender e satisfação pessoal" (p. 153).

Krasilchik (2009) explica que a postura discente é dependente da disciplina, do professor, do momento do curso em que está, o que revela que um aluno superficial em uma disciplina pode ser profundo em outra. A pesquisadora salienta que há evidência de que quando os cursos tomam iniciativas que envolvem discentes nas atividades que estão além da mera frequência nas aulas, eles podem evoluir de alunos superficiais para profundos. Essa situação exige mudanças na postura dos professores universitários, o que é também fator de tensão atualmente. Ou seja, o professor tem novas funções e obrigações. A autora coloca a "necessidade de amalgamar a cultura impressa preponderante em todas as atividades acadêmicas com a cultura digital, cada vez mais significativa, necessária e presente" (p. 154).

O outro aspecto de mudança no ensino superior destacado por Masetto (2003) é no perfil do professor de especialista/transmissor de conhecimento para mediador da aprendizagem. Tal transformação volta-se para a concepção de que o docente não é o foco do processo, mas sim o aluno. Isso implica em compreender que professor e alunos são parceiros, corresponsáveis pela aprendizagem.

Antonio Cunha (2015) aborda sobre o baixo estatuto social do magistério no Brasil enfatizando que ele contribui muito para o mal-estar docente. 
Desse modo, o estudioso elencou que as condições de trabalho, os salários baixos, a falta de perspectiva de futuro profissional e a fluidez da função do professor são fatores que agravam essa sensação de mal-estar e que possuem como base a crise social e a massificação do ensino.

O autor supracitado explica ainda a existência de fatores internos e externos à profissão do professor que contribuem para um mal-estar generalizado da docência que se concretiza na crise identitária do professorado, são alguns deles: exigências no sobre o papel do professor, inúmeras tarefas e imprevisibilidade do cotidiano (Imbernón, 2011; Cunha, 2015), Acrescentamos ainda ao exposto, o conflito de imagem que observamos existir entre o que o professor vê da sua profissão e a representação social dos docentes como um dos motivos que levam alguns autores como Cardoso (2011) a discutirem sobre um movimento de "desprofissionalização" do magistério.

Para Garcia (1988 citado por Cunha, 2015. p. 39) existem seis sintomas que levam à desprofissionalização e ao consequente mal-estar dos professores: burocratização, proletarização, solidão, carreira docente plana, individualismo fragmentado e balcanização. Diante dessas questões, refletimos que para de fato se construir uma identidade bem estabelecida, é necessário que haja um bom processo de formação de professores e desenvolvimento profissional, pois compreendemos que uma identidade bem consolidada é um dos caminhos para a transformação da sociedade e melhoras na profissão do professor, além de contribuir para a qualidade da educação em geral.

Consideramos, com isso, que o significado social que os próprios docentes atribuem a si mesmos influem diretamente na constituição da identidade dos professores. É nesse sentido que Pimenta e Anastasiou (2014) depositam esperanças na reflexibilidade crítica sobre as práticas (Nóvoa, 1995) como alternativa para a valorização do magistério, daquilo que fazem em sala e como possiblidade de reconstrução permanente da identidade pessoal.

Há dois modelos sobre a docência segundo
Cardoso (2011): uma é a imagem de docência como sacerdócio ou vocação e a outra refere-se à imagem de professores como trabalhadores do ensino. Na primeira, se sobressai a imagem de sujeito abnegado que tem uma nobre missão, gerando a desprofissionalização docente. Já na segunda, acredita-se que o docente se assemelha aos operários em seu trabalho, noção essa que visa romper com a ideia de vocação que paira no magistério que, por sua vez, exclui o processo de formação e profissionalização como importantes. Para Cardoso (2011) ambas imagens revelam contextos sócio-históricos específicos que se entrecruzam, se questionam e se reelaboram.

Avalos (2006 citado por Cardoso, 2011) destaca a emergência de uma nova profissionalidade na contemporaneidade que contrapõe o profissionalismo tradicional. No mesmo contexto, Imbernón (2011), ao abordar a necessária redefinição de docência na atualidade, enfatiza que é preciso formar professores críticos e criativos que sejam autônomos e capazes de tomar decisões coerentes com a sua prática e que não se limitem ao domínio de conhecimento científico superando a ideia de professor como um técnico, isso já não é o suficiente hoje.

Ao corroborar com as ideias anteriores, Pimenta e Anastasiou (2014, p. 77) afirmam que uma identidade profissional se constrói a partir da significação social da profissão, nos significados sociais atribuídos a ela e também,

(...) pelo significado que cada professor,
enquanto ator eautor, confere à atividade
docente no seu cotidiano, com base em
seus valores, em seu modo de situar-se
no mundo, em sua história de vida, em
suas representações, em seus saberes,
em sua vida o ser professor (...) mediante
sua rede de relações com outros pro-
fessores, nas instituições de ensino, nos
sindicatos e em outros agrupamentos.

Portanto, acreditamos que valorizar o trabalho docente significa dotar os docentes de perspectivas de análise que os ajudem a compreender os contextos nos quais atuam. Ou seja, os processos continuados de profissionalização seriam um caminho para a construção da identidade (Pimenta \& Anastasiou, 2014). 


\section{A pesquisa: procedimentos éticos e metodológicos}

A investigação é de abordagem qualitativa (Bogdan \& Biklen, 1994) em que os participantes são trinta se seis (36) professores que atuam em cursos de licenciatura de uma universidade pública estadual localizada no Paraná

A coleta dos dados foi realizada como fase preliminar de uma tese de doutorado que teve início no ano de 2015 e investigou a identidade profissional dos formadores de professores. Para essa primeira etapa, o instrumento utilizado foi um questionário aplicado via formulário online (Google Docs) no ano de 2016.

O objetivo da pesquisa consiste em identificar e analisar os desafios que os docentes universitários formadores enfrentam na contemporaneidade. Compreender as identidades profissionais dos professores formadores exige o entendimento das representações que os próprios docentes possuem sobre a sua profissão e as atividades que desenvolvem cotidianamente. Desse modo, no presente artigo focamos nos dados originados a partir de uma das perguntas centrais do nosso questionário, a saber: quais os desafios que o professor do ensino superior enfrenta?

\section{Participantes}

O estudo conta com procedimentos éticometodológicos, dentre eles, evidenciamos que todos os participantes aqui mencionados foram devidamente informados sobre os objetivos e intenções da pesquisa e do mesmo modo consentiram sua participação. Além da submissão e aprovação do projeto de pesquisa pela Plataforma Brasil.

Na Tabela 1 apresentamos o perfil de caracterização dos professores pesquisados.

TABELA 1 - Caracterização dos sujeitos pesquisados

\begin{tabular}{|c|c|c|c|}
\hline VARIÁVEIS & SUBCATEGORIA & N SUJEITOS & $\%$ \\
\hline \multirow{2}{*}{ Gênero } & Feminino & 25 & 69,44 \\
\hline & Masculino & 11 & 30,55 \\
\hline \multirow{4}{*}{ Idade } & De 24 a 30 anos & 3 & 8,33 \\
\hline & De 31 a 40 anos & 10 & 27,77 \\
\hline & De 41 a 53 anos & 22 & 61,11 \\
\hline & Não respondeu & 1 & 2,77 \\
\hline \multirow{4}{*}{ Titulação } & Pós-doutorado & 2 & 5.55 \\
\hline & Doutorado & 13 & 36,11 \\
\hline & Doutorado em andamento & 11 & 30,55 \\
\hline & Mestrado & 10 & 27,77 \\
\hline \multirow{4}{*}{$\begin{array}{c}\text { Regime de } \\
\text { trabalho } \\
\text { semanal }\end{array}$} & $20 \mathrm{~h}$ & 1 & 2,77 \\
\hline & $40 \mathrm{~h}$ & 11 & 30,55 \\
\hline & 40 h com dedicação exclusiva & 21 & 58,33 \\
\hline & Mais de $40 \mathrm{~h}$ & 3 & 8,33 \\
\hline \multirow{3}{*}{ Cargo } & Professor efetivo & 26 & 72,22 \\
\hline & Professor colaborador & 9 & 25 \\
\hline & Não especificou & 1 & 2,77 \\
\hline
\end{tabular}




\begin{tabular}{|c|c|c|c|}
\hline VARIÁVEIS & SUBCATEGORIA & $\mathbf{N}^{\circ}$ SUJEITOS & $\%$ \\
\hline \multirow{3}{*}{$\begin{array}{c}\text { Área de } \\
\text { vinculação } \\
\text { funcional }\end{array}$} & Ciências Biológicas e da Saúde & 7 & 19,44 \\
\hline & Ciências Exatas e Naturais & 5 & 13,88 \\
\hline & Ciências Humanas, Letras e Artes & 24 & 66,66 \\
\hline \multirow{11}{*}{$\begin{array}{c}\text { Departamento/ } \\
\text { lotação }\end{array}$} & DEBIO - Departamento de Biologia Geral & 4 & 11,11 \\
\hline & DEDUFIS - Departamento de Educação Física & 4 & 11,11 \\
\hline & DEQUIM - Departamento de Química & 2 & 5.55 \\
\hline & DEMAT - Departamento de Matemática e Estatística & 3 & 8,33 \\
\hline & DEHIS - Departamento de História & 3 & 8,33 \\
\hline & DEGEO - Departamento de Geociências & 2 & 5.55 \\
\hline & DEEL - Departamento de Estudos da Linguagem & 4 & 11,11 \\
\hline & DEED - Departamento de Educação & 3 & 8,33 \\
\hline & DEPED - Departamento de Pedagogia & 8 & 22,22 \\
\hline & DEARTES - Departamento de Artes & 3 & 8,33 \\
\hline & Totais & 36 & 100 \\
\hline
\end{tabular}

Notamos que a maioria dos sujeitos que participaram da pesquisa é do sexo feminino (69,44\%), possui entre 41 e 53 anos de idade $(61,11 \%)$, com titulação de Doutor (36,11\%). São professores efetivos (72,22\%), ou seja, concursados, e com tempo integral e dedicação exclusiva (TIDE) de trabalho na instituição (58,33\%) e ainda pertencem ao Setor de Ciências Humanas, Letras e Artes $(66,66 \%)$, mais especificamente aos seguintes departamentos: Departamento de História, Departamento de Geociências, Departamento de Estudos e Linguagens, Departamento de Educação, Departamento de Pedagogia e Departamento de Artes Visuais, que, por sua vez, é o setor que mais possui professores atuando nas licenciaturas.

\section{Procedimentos}

Os procedimentos para categorização e análise dos dados pautaram-se nos encaminhamentos metodológicos da Análise Textual Discursiva de Moraes e Galiazzi (2011). Dessa forma, seguindo os passos da ATD, a interpretação sobre os dados coletados foi organizada em três momentos principais: desmontagem dos textos ou unitarização (identificação de significantes nas respostas dos professores), estabelecimento de relações ou categorização, captação do novo emergente e, por fim, a geração do processo auto-organizado que permite identificação daquilo que é novo nos dados estabelecendo-se relações com o referencial teórico e permitindo inferências nos resultados.

O tratamento e a organização dos dados materializaram-se inicialmente com a identificação dos significantes nas respostas dos professores pesquisados, o que nos permitiu na sequência, a construção de três categorias representantes dos resultados do nosso estudo. Os dados serão apresentados da seguinte forma: em primeiro lugar o nome da categoria que será analisada; em seguida apresentamos alguns trechos das falas dos professores que caracterizam a referida categoria e, finalmente, tecemos alguns comentários sobre as falas apresentadas relacionando-as com o referencial teórico por nós utilizado. 


\section{Resultados e discussões}

Identificamos três categorias emergentes que compõem o agrupamento das respostas dos sujeitos pesquisados para essa questão. A Tabela 2 explicita as categorias identificadas e revela a quantidade de respostas dos sujeitos que se enquadram nela.

TABELA 2 - Categorias emergentes da pesquisa

\begin{tabular}{ll}
\hline \multicolumn{1}{c}{ Categoria } & \multicolumn{1}{c}{ Sujeitos } \\
\hline $\begin{array}{l}\text { Categoria I - Desafios relacionados com } \\
\text { a preparação dos alunos para o ensino } \\
\text { superior }\end{array}$ & $\begin{array}{l}\text { P1, P2, P4, P5, P9, P11, P15, P16, P17, P20, P21, P24, P25, P28, } \\
\text { Total 19, P31, P34 e P35 }\end{array}$ \\
$\begin{array}{l}\text { Categoria II - Desafios relacionados com } \\
\text { as politicas públicas educacionais e com } \\
\text { o contexto educacional atual }\end{array}$ & P33, P35 e P36 \\
Total 17 \\
$\begin{array}{l}\text { Categoria III - Desafios relacionados com } \\
\text { as condições profissionais }\end{array}$ & P1, P3, P7, P8, P10, P14, P20, P21, P23, P26, P29, P31, P35 e P36 \\
\hline
\end{tabular}

\section{Categoria I - Desafios relacionados com a preparação dos alunos para o ensino superior.}

Os desafios identificados pelos professores pesquisados pertencentes a essa primeira categoria dizem respeito à visão dos professores universitários sobre como os alunos chegam até a graduação. Os professores citaram com frequência significativa a defasagem na formação básica dos alunos que ingressam no ensino superior, mais especificamente nos cursos de licenciatura, como nota-se com a resposta de P11:

\begin{abstract}
Tem a ver com a má formação dos alunos, advinda do Ensino Fundamental e Médio. Principalmente na relação com a linguagem escrita e com a capacidade de abstração conceitual e raciocínio lógico. Em diversos momentos, ou beira o desesperador, ou resulta em 'desistir' estrategicamente, momentaneamente, nivelando por baixo (...). Não sei se é uma questão de maior acesso da população ao ensino superior, ou numa piora da qualidade do ensino fundamental e médio. (P11, questionário, 14 Mar. 2016)
\end{abstract}

Também destacaram os participantes da pesquisa que dentre os desafios está a falta de comprometimento e interesse dos discentes com a sua própria formação profissional, que se exemplifica na resposta de P29 abaixo. Sobre isso, identificamos o quanto é necessário refletir/pensar sobre quem são os alunos que estão nas licenciaturas, afinal, o professor trabalha a fim de ensinar esses sujeitos, fazer com que eles aprendam de fato.
Estou falando de uma sociedade que não entende o que é a Universidade. (...). Isso afeta todos os aspectos da vida profissional, desde a autoestima até a falta de noção de responsabilidade dos alunos. Indiretamente isso também se relaciona às péssimas condições de aprendizado nas quais os alunos chegam até nós, pois advém de um Ensino Fundamental mais sucateado que o Ensino Superior. Surge então o desafio de manter um nivel de exigência de Graduação, com alunos que na verdade não tem condições para tanto. E digo também de condições emocionais: me deparo com alunos de baixa autoestima e crença de autoeficácia, resultados desse descaso que paira no imaginário brasileiro. Em minha opinião, a Educação brasileira como um todo sofre violências cotidianas, por conta do lugar simbólico contraditório que ocupa em nossa cultura. É nesse sentido que estou falando menos em dinheiro e mais em valores culturais. (P29, questionário, 29 Mar. 2016)

Entendemos que a relação entre professor e aluno é condicionante de qualidade no processo de aprendizagem, isso porque a nossa concepção baliza-se na premissa de que o aluno só aprende se ele for mobilizado e estiver envolvido no processo, considerando-se como sujeito coparticipante, como bem colocou Masetto (2003).

Compreendemos que a relação entre teoria e prática é uma relação que envolve os diferentes saberes para o exercício do magistério superior explicitados por Pimenta e Anastasiou (2014) e que perpassa, principalmente, pelo conhecimento 
que o professor tem do contexto e de seus alunos. Tal relação nem sempre é fácil de ser demonstrada no processo de ensino, bem como colocou o professor P28:

Demonstrar que o conhecimento teórico tem importância na ação profissional. A produção de conhecimento é importante para o desenvolvimento da sociedade como um todo. Reflexão sobre os fatos, conhecimentos e ações em todos os aspectos sociais. Existe relação direta entre quem você é e suas atitudes. (P28, questionário, 25 Mar. 2016)

Percebemos também no discurso dos docentes que eles se sentem desafiados a motivar os alunos para que participem de fato do processo de ensino e de aprendizagem a para a carreira de professor. Esse sentimento vai ao encontro do que Krasilchik (2009) destaca como as consequências e as tensões que permeiam o trabalho na universidade e que afetam diretamente a sala de aula e interferem nas atividades acadêmicas e na formação profissional.

As respostas dos professores representativas dessa categoria reforçam o que Krasilchik (2009) coloca quando enfatiza que é preciso analisar a postura dos estudantes e o professor necessita se enxergar como orientador do processo, mediador (Masetto, 2003). Para Krasilchik (2009) a postura do aluno é dependente da disciplina, do professor, do momento do curso em que está, ou seja, os fatores influentes são múltiplos o que realmente constitui um desafio ao docente perceber seus alunos e encontrar estratégias que os faça evoluir, o que foi observado nos discursos dos professores formadores pesquisados.

Em dois estudos anteriores realizados por nós (Mendes \& Baccon, 2015; Mendes, Clock, \& Baccon, 2016) com professores da educação básica estadual do Paraná, o mesmo grupo de docentes foi indagado por meio de entrevista com oito (8) sujeitos sobre os desafios da docência (Mendes \& Baccon, 2015) e através de questionário com cento e cinquenta e sete (157) docentes sobre os aspectos positivos e negativos da profissão docente (Mendes, Clock, \& Baccon, 2016).

Como resultado das entrevistas, as autoras
(Mendes \& Baccon, 2015) revelaram que os docentes da educação básica identificam que os principais desafios da docência se atrelam às relações interpessoais em sala de aula enfatizando que o professor precisa ser "amigo" do aluno.

Já no estudo que buscou identificar os aspectos positivos e negativos da profissão docente (Mendes, Clock, \& Baccon, 2016), os resultados apontaram que, dentre os aspectos positivos, estão, respectivamente: relações interpessoais, reconhecimento do seu papel pelo outro (sociedade) e possibilidade de transformar a sociedade. Ou seja, ao mesmo tempo que a interação interpessoal que se faz em sala de aula é desafiante, ela também traz prazer e satisfação ao docente.

Desse modo, inferimos que os docentes da educação básica investigados por Mendes e Baccon (2015) e Mendes, Clock e Baccon (2016) preocupam-se mais com as relações interpessoais vivenciadas na escola do que com questões voltadas ao ato de ensinar ou à prática da docência. Diferentemente disso, o professor do ensino superior demonstrou na presente pesquisa valorizar a relação professor-aluno de outra maneira, compreendendo que tal relação é determinante para que ele, enquanto mediador, consiga de fato motivar os alunos a aprender, instigar o desejo de aprender.

Em outras palavras, o docente da educação básica preocupa-se com uma relação afetiva diferente pois, muitas vezes, a sua preocupação ou desafio está em manter uma relação em que o aluno "simpatize" com ele, "goste" da sua presença para que sejam "amigos", isto porque o aluno analisando o professor como "amigo" e deixa de "atrapalhar" as aulas, incomodar os colegas, diminuindo o que denominam como indisciplina.

Averiguamos (Mendes, Clock, \& Baccon, 2016) que os professores da educação básica identificaram como fatores positivos da docência àqueles que remetem à dimensão do professor como pessoa revelando as suas satisfações e desejos intrinsecos para permanecer na docência. Concluímos no estudo citado que o envolvimento do professor com pessoas e as relações interpessoais que ele vivencia na escola são 
fatores extremamente importantes para o sujeito que escolhe ser professor e ainda é fator que o ajuda a manter-se na carreira. Desse modo, a satisfação profissional dos docentes perpassa, em primeiro lugar, pelo reconhecimento do seu papel pelo outro (alunos, colegas, sociedade etc.). Em segundo lugar, pela possibilidade que ele tem de gerar transformações na sociedade por meio de seu trabalho e, em terceiro lugar, pelas relações interpessoais que se estabelecem no decorrer do processo de ensino e de aprendizagem.

Como complemento ao que já constatamos em estudos anteriores (Mendes \& Baccon, 2015; Mendes, Clock, \& Baccon, 2016), na presente pesquisa com professores formadores do magistério superior concluímos que as posturas dos alunos podem ser geradoras de uma grande insatisfação para os docentes pois fogem às suas expectativas. Observamos que tal situação provoca preocupações com relação à formação desses futuros professores no sentido de como esses alunos chegam à graduação, quais conhecimentos e saberes gerais e profissionais possuem e como foi a sua formação básica no ensino fundamental e ensino médio.

Constatamos que os licenciandos, a partir dos discursos dos professores pesquisados, não possuem preparação básica ou uma formação adequada e, em alguns casos, não possuem maturidade o suficiente para compreender a responsabilidade e o compromisso que são inerentes à profissão docente e devem ser assumidos desde a formação inicial docente. Esses são considerados por nós como fatores contribuintes para o mal-estar docente. Com isso, analisamos que há consciência de que o processo de ensino e aprendizagem só se efetiva se houver disposição do alunado. Os alunos precisam querer, desejar aprender. E para ter alunos motivados e mantê-los motivados existe uma gama de fatores que fogem ao controle do professor, o que, em nosso entendimento, revela um dos maiores desafios da docência, seja ela na educação básica ou no ensino superior.

Evidenciamos aqui a característica que, em nossa percepção, diferencia a profissão docente das demais profissões: o fato dela ser extremamente relacional. Isso significa que ser professor se constrói e se efetiva por meio da relação que se estabelece entre professoraluno-conhecimento. Para que aconteça essa relação de modo harmonioso e que se promova aprendizagem discente, que é seu objetivo, o professor, como ator e autor necessita ter consciência do seu papel enquanto mediador da relação e, para isso, precisa conhecer quem são os seus alunos no sentido de buscar compreender as motivações pelo curso, atrativos da disciplina de modo que permitam uma organização e uma sistematização do conteúdo eficazes.

Categoria II - Desafios relacionados com as políticas públicas educacionais e com o contexto educacional atual. Os desafios que os docentes universitários enfrentam que pertencem a essa categoria relacionam-se intimamente com o contexto maior da sociedade, com a estrutura em sua dimensão macro, isto é, com as transformações da contemporaneidade como colocou Imbernón (2011). Os professores mencionaram questões de ordem das politicas públicas educacionais e as suas influências na docência universitária; questões de financiamento e investimento na educação brasileira e nas universidades e o quanto isso afeta o trabalho docente. Observamos como essas questões aparecem enfatizadas pelos professores nessa categoria nos seguintes exemplos de respostas:

Desvalorização da carreira docente. Políticas institucionais que muitas vezes não atentam para o objetivo principal da educação, que é a aprendizagem do acadêmico. (P1, questionário, 14 Mar. 2016)

A gradativa perda dos direitos em relação à profissão por questões políticas do pais é um dos desafios. (P32, questionário, 30 Mar. 2016)

Falta de apoio dos governos, falta de compromisso com a educação pública de qualidade, desvalorização da profissão, falta de estrutura. (P35, questionário, 30 Mar. 2016)

Verificamos nos discursos dos formadores pesquisados alguns dos fatores (internos e externos) que Cunha (2015) destaca como 
contribuintes para o mencionado mal-estar, dentre eles: a fluidez da função docente, a crise social e a massificação do ensino. Constatamos que tais fatores fazem parte de um contexto maior em que as consequências do neoliberalismo e da ideologia da qualidade total imperam. Retomamos as colocações de Severino (2002), que mostram que o excessivo trabalho burocrático, a ausência de projetos de ações que superem interesses egocêntricos e imediatos do mercado de trabalho são as marcas do contexto social atual e deixam consequências a todos os setores da sociedade.

Alguns dos fragmentos das respostas dos docentes que pertencem à categoria II indicam ainda a desvalorização e a falta de reconhecimento da carreira docente e estão ligadas ao estatuto social baixo que tem a docência no Brasil conforme apontado por Cunha (2015) e que colabora para o mal-estar docente que assombra os profissionais dos diferentes niveis de ensino. Vejamos:

Acredito que muitos são os desafios, mas a falta de reconhecimento perante a sociedade, o descaso de certos políticos referente aos cursos de licenciaturas e porque não dizer até da falta de ética profissional que estamos enfrentando nos dias de hoje. (P22, questionário, 17 Mar. 2016)

Desvalorização das licenciaturas, falta de verbas e estrutura para desenvolver seu trabalho, burocratização das ações internas na universidade, lentidão da universidade para acompanhar mudanças necessárias no curso, biblioteca não atualizada. (P33, questionário, 30 Mar. 2016)

Os desafios da docência universitária que se encaixam nessa categoria, conforme os docentes pesquisados, apontam para o contexto maior da educação que presenciamos em nosso País, que são efeitos/consequência da globalização e do capitalismo (Krasilchik, 2009; Severino, 2002).

Krasilchik (2009) colocou que, no que tange ao ensino superior, a globalização constitui um conjunto das forças sociais, econômicas e tecnológicas que afetam a nossa realidade e, ainda, exige dos professores mudanças e um perfil diferenciado, o que também é mencionado por Imbernón (2011) ao enfatizar uma necessária redefinição da profissão docente nos dias atuais. Essas questões corroboram com a ideia de que não há instituição de educação que seja isolada da sociedade como um todo, ela faz parte, portanto, gera influência e recebe influências de tudo que está no seu redor.

Questões como essas se revelam muito claramente nos discursos dos professores quando eles citam as influências das politicas no seu trabalho. Desse modo, citamos Cardoso (2011) ao destacar que a identidade docente é afetada por uma multiplicidade de fatores, inclusive pelas reflexões que se fazem em torno das políticas educacionais, uma vez que elas são resultantes de conflitos, rearranjos e compromissos em que se entrevem diversos atores. Por isso que se torna importante conhecer as identidades docentes para entender melhor a sua relação com os demais segmentos do campo educacional, pois as transformações e regulações dependem desses atores por meio de negociações e confrontações.

Uma proposta para superar esse desafio, pode ir ao encontro do que Severino (2002) destacou: o aprender e o ensinar a partir da pesquisa. No mesmo sentido, Pimenta e Anastasiou (2014) abordaram a questão da valorização da pesquisa no processo de ensinar que também pode produzir outro olhar/ outra visão tanto para o aluno como para o professor no contexto de ensino e de aprendizagem.

Os aspectos identificados nas falas dos professores formadores apontam ainda que, de certa forma, a universidade não está conseguindo cumprir totalmente o papel e a função indicados por Pimenta e Anastasiou (2014). Além disso, percebemos que, atualmente, as políticas públicas educacionais não têm valorizado a universidade como espaço de construção de conhecimento (Chauí, 2001; Pimenta \& Anastasiou, 2014), o que é reflexo também da visão da sociedade sobre a universidade que demonstra que tem se apoiado mais em uma racionalidade técnica e instrumental.

Notamos ainda que os professores pesquisados percebem que não estão recebendo o apoio necessário para desempenhar o seu papel e para construir o conhecimento de modo crítico 
e para buscar a tão almejada indissociabilidade entre ensino, pesquisa e extensão. Os mesmos reconhecem que "A profissão de professor exige de seus profissionais alteração, flexibilidade, imprevisibilidade. (...). A experiência acumulada serve apenas de referência, nunca de padrão de ações com segurança e sucesso." (Pimenta \& Anastasiou, 2014, p. 199). Entretanto, revelaram que o contexto maior tem buscado a formação e a atuação de professores técnicos, cumpridores de tarefas, o que causa conflito entre aquilo que fazem e aquilo que acreditam (real versus ideal).

Observamos que as mesmas características que foram colocadas na categoria II pelos docentes do ensino superior já haviam sido mencionadas na pesquisa anterior realizada por nós com docentes da educação básica (Mendes, Clock, \& Baccon, 2016). Especialmente quando os professores atribuem como característica negativa principal da profissão docente, questões que envolvem as condições de trabalho e aspectos organizacionais os quais incluem, nas palavras deles: sobrecarga de tarefas, baixa valorização, falta de reconhecimento, falta de estrutura, falta de material didático e espaço, dentre outros.

O resultado de ambas as pesquisas demonstra que o mal-estar, a insatisfação e os desafios de professores tanto da educação básica como da superior são consensuais e estão relacionados com o sistema educacional brasileiro e com o "como" a sociedade tem valorizados a profissão do professor como um todo.

\section{Categoria III - Desafios relacionados com as} condições profissionais. Ainda dentre os desafios que os professores elencaram que enfrentam na docência universitária estão aqueles relacionados às condições profissionais, à carreira docente, às instituições em que trabalham e à formação de professores em geral. Ressaltamos que esses desafios estão intimamente relacionados com os mencionados na categoria II.

Os professores pesquisados destacaram que as muitas tarefas e afazeres que um docente universitário possui, o excesso de tarefas de cunho burocrático e administrativo, a constante cobrança pela produtividade e as condições estruturais dificultam o ensino e o desenvolvimento de suas pesquisas. Segue abaixo um fragmento de respostas que ilustra essa categoria:

Condições dignas de trabalho (espaço físico adequado/atualização e manutenção de equipamentos, segurança): multiplicidade de tarefas e responsabilidades complementares ao processo de ensino; desconstrução do trabalho coletivo que o fazer docente necessita. (P10, questionário, 15 Mar. 2016)

Percebemos que os professores colocam os desafios da docência universitária relacionados com a sobrecarga de atividades que possuem e também se referem à falta de recursos adequados na universidade. Compreendemos que se associam à falta de estrutura e vão ao encontro da "sensação generalizada de frustração" que assombra o trabalho docente, conforme Severino (2002) destacou quando citou que o excesso de trabalho burocrático colabora para o processo de "corrosão interna" das instituições de ensino superior, comprometendo a eficácia do ensino. Tais fatores só são agravados quando analisamos a atual condição das universidades públicas brasileiras, o descaso das iniciativas públicas, a desvalorização do professor universitário e a sua carreira, o sucateamento e a retirada de investimentos para a pesquisa.

Falta de pessoal administrativo e estruturas físicas e humanas. (P8, questionário, 14 Mar. 2016)

A falta ou baixa disponibilidade de recursos que poderiam facilitar as atividades (não apenas financeiros, mas de espaço, funcionários, livros etc). (P2O, questionário, 21 Mar. 2016)

Nessa categoria, também identificamos nas falas dos professores uma cobrança por produtividade ou "produtivismo acadêmico", conforme destacam os professores abaixo:

Precariedade no custeio e investimento das IES, acúmulo de frentes de trabalho, pressão por produtivismo acadêmico. (P21, questionário, 21 Mar. 2016)

Cobrança pelo produtivismo; múltiplas tarefas (atividades pedagógicas, administrativas, políticas, etc.). (P26, questionário, 23 Mar. 2016) 
Contrariamente do que se espera dos governantes e das políticas, os professores estão sendo "massacrados" com atividades burocráticas que os consomem e não os deixam cumprir a sua verdadeira função. Verificarmos nos discursos dos professores alguns dos fatores (internos e externos) que Cunha (2015) destaca como contribuintes para o mencionado mal-estar, dentre eles as condições de exercício profissional, a fluidez da função docente, a crise social e a massificação do ensino.

Destacamos também o conflito de imagem entre o que o professor vê da sua profissão e o que a sociedade percebe, uma das causas do já mencionado movimento de desprofissionalização docente (Cardoso, 2011). Sobre os sintomas que levam a tal movimento, Garcia (1988 citado por Cunha, 2015, p. 39) explicou que são: burocratização, proletarização, solidão, carreira docente plana, individualismo fragmentado e balcanização; confirmamos tais sintomas nos discursos docentes que se enquadram nessa categoria.

As respostas dos docentes que estão relacionadas à sobrecarga nos evidenciam as consequências e as tensões que permeiam o trabalho na universidade, desembocando diretamente na sala de aula e interferindo nas atividades acadêmicas, conforme explicou por Krasilchik (2009).

Juntamente com a sobrecarga de tarefas, ficou evidente também uma pressão em relação ao "produtivismoacadêmico", que se revela em cobrança pela quantidade de produções acadêmicas dos professores, provocando diminuição da qualidade das mesmas, o que é contrário ao que Pimenta e Anastasiou (2014) colocaram, que deve existir uma valorização da pesquisa.

Os discursos dos professores mencionados aqui também reforçam o mal-estar docente (Cunha, 2015), causados pelas exigências referentes ao desempenho do papel do professor, ao excesso de tarefas, além das situações imprevisíveis e invisiveis a qual se deparam no cotidiano da sala de aula (Imbernón, 2011).

Identificamos que os desafios elencados pelos professores universitário estão na contramão do que Krasilchik (2009, p. 157) explicita como fatores que influem no bom desempenho dos professores, os quais são multidimensionais: "entusiasmo, aprendizado dos estudantes, organização, capacidade de criar um clima satisfatório confortável, promover a interação no grupo e ter bom relacionamento com os estudantes", além disso, têm-se também os conteúdos de curso, programa, carga horária como outro grupo de fatores importante para se analisar o desempenho docente.

\section{Algumas considerações}

O objetivo do presente estudo consistiu em identificar e analisar os desafios que os docentes universitários formadores enfrentam na contemporaneidade. Desse modo, ao analisarmos as três categorias emergentes e representativas dos discursos dos professores formadores, identificamos que esses desafios estão relacionados ao processo de ensino e aprendizagem; às condições profissionais e à falta de políticas públicas, à desvalorização da carreira docente e ao contexto social atual.

Podemos afirmar, ainda, que a atual conjuntura nos evidencia que há muitas contradições quando abordamos o papel que se espera das universidades e o papel que elas realmente têm desempenhado. Dentre essas contradições citamos a tão discutida "indissociabilidade" entre ensino, pesquisa e extensão, apontada por Cunha (2012), quando se analisa as concepções e práticas sobre o que é ensinar com pesquisa, ensinar a pesquisar, o que de fato é ser um professor pesquisador, que acaba se configurando como uma "confusão", de forma obscura e cobrada na forma de produtivismo.

Compreendemos que os docentes universitários participantes da presente pesquisa têm a concepção de que professores são como trabalhadores do ensino explicada por Cardoso (2011). Ou seja, analisam o professor como um profissional que atua em função do ensino e valoriza a formação e a profissionalização. Em contrapartida, os docentes da educação básica participantes do estudo de Mendes, Clock e Baccon (2016) revelaram uma concepção de docência mais atrelada à noção de "vocação", 
de um sujeito que possui uma missão nobre de transformar a sociedade (Cardoso, 2011).

Podemos destacar que a universidade, como maior instituição de formação de professores, tem um papel primordial no desenvolvimento profissional docente. Entretanto, não podemos deixar de levar em consideração que o professor formador é um dos sujeitos-chave nesse contexto. Portanto, o professor formador precisa se sentir parte da sua universidade como pesquisador, como ator e como autor que contribui para a mudança e a construção social, e que tem consciência das suas escolhas pedagógicas, sabe o que está fazendo e compreende as diferenças entre ensinar com pesquisa e ensino para a pesquisa.

Os professores pesquisados evidenciaram ainda a concepção de que o aluno é o centro do processo de ensino e de aprendizagem (Masetto, 2003) e, também, demonstraram que possuem uma preocupação com o desafio que possuem de fazer com que os alunos se analisem como tal, se considerem como sujeitos ativos e se coloquem nessa posição. Esse desafio pode ter como fundamento o fato de que a educação básica ainda não conseguiu "desfazer-se" do ensino transmissivo. Se na educação básica os alunos foram considerados como sujeitos passivos, como fazer com que, na graduação, transformem-se em sujeitos ativos?

Outra questão que se demonstrou em nosso estudo como importante, e uma demanda emergente, é a de refletir sobre quem são os alunos que frequentam as licenciaturas. Para uma análise eficaz e conclusões mais precisas sobre isso torna-se necessário verificar as motivações dos alunos para buscar a formação de professores, as suas expectativas, investigar como foi a sua formação básica. Com isso, há também a demanda de que as iniciativas de formação continuada dos professores formadores ofereçam condições para que os docentes reflitam sobre os processos de aprendizagem de adultos.

Compreendemos que a "culpa" não é só do aluno, mas do sistema educacional como um todo envolvendo as politicas educacionais e de formação e as práticas docentes. Reforçamos que mudar não é simples. É um processo a longo prazo e envolve muitas pessoas e estruturas. Por isso, depositamos expectativas nos esforços atuais e nas discussões sobre desenvolvimento profissional docente, mais especificamente no desvelamento da identidade docente. Só conhecendo as configurações atuais de identidade dos professores para podermos, com mais eficácia, refletir sobre as estratégias de formação.

A sensação que temos é a de que o tempo passa, mas a crise e o mal-estar docentes só se intensificam. Apesar da consciência de muitos atores e setores da sociedade sobre a importância do docente, do seu trabalho e também da formação de professores na perspectiva do desenvolvimento profissional, as coisas parecem não melhorar efetivamente.

\section{Agradecimento}

O presente trabalho foi realizado com apoio da Coordenação de Aperfeiçoamento de Pessoal de Nivel Superior - Brasil (CAPES) - Código de Financiamento 001 e com apoio da Fundação Araucária.

\section{Referências}

Bogdan, R., \& Biklen, S. (1994). Investigação qualitativa em Educação: uma introdução à teoria e aos métodos. Portugal: Porto Editora.

Cardoso, M. E. (2011). Identidade(s) docente(s): aproximações teóricas. In D. A., Oliveira, M. E. Pini, \& M. Feldfeber. (Orgs.). Politicas educacionais e trabalho docente: perspectiva comparada. (pp. 187-212). Belo Horizonte: Fino Traço.

Chaui, M. de S. (2001). Escritos sobre a universidade. São Paulo: UNESP. https://doi. org/10.7476/9788539303045

Cunha, A. C. (2015). Ser professor: bases de uma sistematização teórica. Chapeco: Argos.

Cunha, M. I. da. (2012). A indissociabilidade do ensino com a pesquisa e a extensão como referente da qualidade na universidade brasileira: um discurso em tensão. In M. I. da Cunha (Org.). Qualidade da graduação: a relação entre ensino, pesquisa e extensão e o desenvolvimento profissional docente (pp. 17-38). Araraquara: Junqueira \& Marin.

Hey, A. P. (2008). Fronteira viva: o campo acadêmico e o campo político no Brasil. In M. L. N. de Azevedo (Org.). Políticas públicas e educação: debates contemporâneos (pp. 217-230). Maringá, PR: EDUEM. 
Imbernón, F. (2011). Formação docente e profissional: formar-se para a mudança e a incerteza. 9. ed. v. 14. São Paulo: Cortez.

Krasilchik, M. (2009). Docência no ensino superior: tensões e mudanças. In S. G. Pimenta \& M. I. de Almeida (Orgs.). Pedagogia universitária (pp 147-164). São Paulo: EdUSP.

Masetto, M. T. (2003). Competência pedagógica do professor universitário. São Paulo: Summus.

Mendes, T. C., \& Baccon, A. L. P. (2015). Tornar-se e ser professor: os desafios da docência. Revista Hipótese, Itapetininga, 1(4), 161-180.

Mendes, T. C., Clock, L. M., \& Baccon, A. L. P. (2016). Aspectos positivos e negativos da profissão docente: entre a satisfação e o desejo do professor. Com a Palavra o Professor, Vitória da Conquista (BA), 1(1), 7392. https://doi.org/10.23864/cpp-v1-n1-33

Moraes, R. C. C. de. (1998). Universidade hoje - Ensino, pesquisa, extensão. Educação e Sociedade, Campinas, 19(63), 19-37. https://doi.org/10.1590/ S0101-73301998000200003

Moraes, R. \& Galiazzi, M. do C. (2011). Análise textual discursiva. (2. ed.) ljuí: Unijuí.

Nóvoa, A. (1995). Formação de professores e profissão docente. In Os professores e sua formação. (2. ed., pp. 13-33). Lisboa: Dom Quixote.

Pimenta, S. G. \& Anastasiou, L. das G. C. (2014). Docência no ensino Superior. (5. ed.). São Paulo: Cortez.

Severino, A. J. (2002). Educação e universidade: conhecimento e construção da cidadania. Interface, Comunicação, Saúde, Educação, 6(10), 117-24. https://doi.org/10.1590/S1414-32832002000100015

Soares, S. R. \& Cunha, M. I. da. (2010). Formação do professor: a docência universitária em busca de legitimidade. Salvador: EDUFBA. https://doi. org/10.7476/9788523211981

\section{Thamiris Christine Mendes Berger}

Doutora e Mestre em Educação pelo Programa de Pós- graduação em Educação da Universidade Estadual de Ponta Grossa (UEPG, Ponta Grossa, PR, Brasil). Bacharel em Psicologia (IESSA) e Licenciada em Pedagogia (UEPG), Ponta Grossa, PR, Brasil.

\section{Ana Lúcia Pereira}

Doutora e Mestre em Ensino de Ciências e Educação Matemática pela Universidade Estadual de Londrina (UEL, Londrina, PR, Brasil), Professora da Universidade Estadual de Ponta Grossa (UEPG), em Ponta Grossa, PR, Brasil.

\section{Cristina Costa}

Doutora em Educação pela Universidade de Salford (NCUK, Manchester, Inglaterra, Reino Unido), professora da Universidade de Durham (Durham, Inglaterra, Reino Unido).

\section{Endereço para correspondência}

Thamiris Christine Mendes Berger

Rua Omaguás, 142

Jardim Marajoara, 14500-000

Ituverava, SP, Brasil

Ana Lúcia Pereira

Universidade Estadual de Ponta Grossa

Av. General Carlos Cavalcanti, 4748, Bloco L-103

Campus Uvaranas, 84030-900

Ponta Grossa, PR, Brasil

\section{Cristina Costa}

School of Education, Durham University,

Burdon House, office 110

Leazes Rd, Durham DH1 1TA

Durham - England - UK. 